\title{
UNA ENTREVISTA CON CHANTAL MOUFFE ${ }^{1}$
}

James Martin

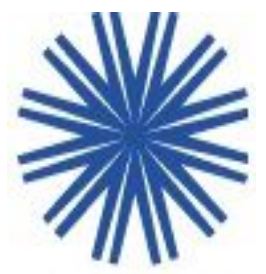

Este volumen es parte de una serie que atañe a 'innovadores' de la teoría política. Su trabajo se ha desarrollado desde una distintiva tradición marxista-gramsciana, pero con los años ha incorporado perspectivas del feminismo y del postestructuralismo y, más recientemente, se ha involucrado con la teoría política anglo-americana. Dada esta rica y compleja articulación de tradiciones ¿dónde ve exactamente que radican sus innovaciones?

Una de las innovaciones que mi trabajo ha introducido en la teoría política consiste en haber articulado perspectivas cruciales de Gramcsi con las obras de algunos postestructuralistas como Derrida y Lacan. Esta es un emprendimiento compartido con Ernesto Laclau que comenzó con nuestra colaboración en Hegemonía y Estrategia Socialista. Muestro propósito fue elaborar una concepción adecuada de la política, alrededor de dos conceptos: antagonismo y hegemonía. En mi trabajo posterior, desarrollo esta aproximación introduciendo la distinción entre antagonismo y agonismo para proponer una nueva comprensión de la naturaleza de la política democrática. Con la teoría política anglo-americana, mi relación es totalmente diferente. Mi involucramiento con ella ha sido de naturaleza crítica. De hecho, cuando comencé a discutir con autores como John Rawls fue porque, después de haber criticado al marxismo por su falta de comprensión de lo político, sentí fuertemente que la solución para la izquierda era no girar hacia el liberalismo, como había sido el caso en los 80, particularmente en Francia. Quería mostrar que no había lugar para lo político en la teoría liberal.

\footnotetext{
${ }^{1}$ Correspondiente al capítulo 15 de James Martin (ed.) Chantal Mouffe. Hegemony, radical democracy and the political, Routledge, New York, 2013. Traducción de José Fernando García.
} 
En ese contexto comencé a interesarme en el trabajo de Schmitt. Encontré su crítica al liberalismo realmente poderosa y pienso que hay mucho que podemos aprender de ella. Quiero enfatizar, sin embargo, que discrepo enérgicamente con sus conclusiones acerca de la imposibilidad de un régimen pluralista democrático. Mi objetivo siempre ha sido -como el título de uno de mis ensayos lo indica- 'trabajar con Schmitt contra Schmitt', usando su crítica no para rechazar la tradición liberal, sino para reformular algunos de sus intuiciones en un modo propiamente político. Arguyo que, para poder concebir la democracia pluralista liberal de un modo adecuado, tenemos primero que reconocer la inerradicabilidad del antagonismo y la imposibilidad de alcanzar un consenso racional inclusivo en política. Necesitamos también captar el proceso de formación de las identidades políticas y el crucial papel que juegan los afectos en ese proceso. Uso el término 'pasiones' para referirme a la dimensión afectiva que está en juego en las formas colectivas de identificación, una dimensión que la teoría política contemporánea se ha esforzado en eliminar de la política democrática. Desde mi punto de vista el principal defecto de la teoría política liberal democrática procede del racionalismo y del individualismo. He intentado en mi trabajo remediar esas deficiencias, desarrollando un enfoque alternativo que tome en cuenta el papel de la negatividad radical y use las ideas del psicoanálisis para comprender el modo en que las identidades políticas colectivas se construyen a través de procesos de identificación.

Usted ha recurrido a la teoría gramcsiana de la hegemonía, desarrollándola más allá de un marco de referencia estrictamente marxista y conectado sus conceptos estratégicamente orientados (tales como 'guerra de posición' o 'intelectuales orgánicos') a términos como 'discurso', indecidibilidad' o 'antagonismo'. ¿Desde su perspectiva es la herencia gramcsiana enteramente separable de sus raices marxistas?

Nuestro uso de la teoría de la hegemonía en Hegemonía y Estrategia Socialista es definitivamente 'post-gramcsiana', ya que rechazamos el papel privilegiado que él atribuye a la clase trabajadora. Pero pienso que es en un sentido fiel al espíritu de Gramcsi, quién -me atrevería a sugerir-, habría desarrollado su pensamiento en una dirección similar si hubiera estado confrontado a los cambios provocados por el desarrollo del post-fordismo. Para usar sus conceptos de 'guerra de posición' o 'intelectual orgánico' de un modo creativo, debemos adaptarlos a nuevas situaciones y 
diferentes contextos, no insistir en que su significado estaba fijado de una vez y para siempre por la coyuntura en la que Gramcsi los elaboró. En verdad, lo que encuentro notable en su trabajo es su capacidad de entender el modo en que las condiciones están cambiando y no ser prisionero de ninguna ortodoxia. Gramcsi fue muy receptivo a diferentes perspectivas intelectuales y, como Norberto Bobbio lo ha mostrado, él no descartó la tradición liberal. Estaba muy interesado en el pragmatismo y apreciaba el trabajo de William James. Estoy segura que habría querido incorporar la crítica al esencialismo que se encuentra en varias corrientes de la filosofía de post-guerra. De hecho, muchas de sus intuiciones replican esas críticas. Así, no creo que inscribir los conceptos gramcsianos en un vocabulario post-estructuralista sea separar su herencia de sus raíces marxistas, sino desarrollar su potencial en nuevas direcciones. En todo caso, la cuestión de la 'fidelidad' al marxismo es un asunto en disputa y muchos marxistas tradicionales ya consideraban que Gramcsi era demasiado revisionista.

Su trabajo ha evolucionado en un periodo que abarca transformaciones internacionales mayores, desde el colapso del comunismo, el fin del Apartheid en Sudáfrica, el surgimiento de la 'globalización' neoliberal, así como su resistencia, hasta la política mundial después del '9/11'. ¿Cuán importante es para usted que los teóricos políticos sean sensibles a luchas y conflictos en el más amplio contexto? ¿Ve su trabajo más como un compromiso con las posibilidades de la situación predominante que con 'ideas?

Mi trabajo siempre ha estado orientado por el deseo de entender qué está ocurriendo en el mundo, de modo que sea posible intervenir en él. Creo verdaderamente en el poder de las ideas, de otro modo no habría elegido ser una teórica. Primero estudié filosofía y por varios años enseñé epistemología en la Universidad Nacional de Colombia, en Bogotá. Esto bajo la influencia de Althusser, con el cual había estudiado en Paris. Sin embargo, rápidamente sentí que aquello no tenía suficiente conexión con los asuntos sociales y políticos, así es que volví a Europa a estudiar política. Pero no estaba satisfecha con la disciplina ciencia política, la cual encontraba demasiado empírica. Finalmente, combinando filosofía y política en la teoría política encontré un enfoque que me vino. Me permitió desarrollar ideas que podrían jugar un papel en la política clarificando asuntos importantes para la intervención política. Cuando decido 
examinar un asunto específico mi motivación original es siempre política. Por ejemplo, en el caso de Hegemonía y Estrategia Socialista nuestro propósito fue entender las razones de la incapacidad del marxismo para entender la naturaleza de los nuevos movimientos sociales y presentar un proyecto capaz de articular una diversidad de demandas, no basadas en las clases. Argumentamos que esta incapacidad era debido a una ontología clasista-esencialista y su enfoque economicista que no permitía reconocer que los sujetos políticos estaban construidos discursivamente. Con el fin de superar esas limitaciones recurrimos al post-estructuralismo. Los argumentos del libro fueron elaborados en dos niveles, político y teórico, pero el impulso original fue político. Puedo decir lo mismo de todos mis escritos posteriores. La chispa inicial está siempre dada por una coyuntura política dada. Mi crítica de la democracia deliberativa, por ejemplo, viene de mi convicción de que es vital para la política democrática reconocer el papel de los afectos en política y no abandonar este terreno a la derecha. En On the Political he mostrado cómo la crisis de la izquierda hoy es debida a la falta de comprensión de la necesaria naturaleza 'partisana' de la política y un énfasis erróneo en el consenso. Pienso que el surgimiento de partidos de derecha populistas en Europa está ligado al hecho que los partidos de izquierda fueron incapaces de ofrecer alternativas a la hegemonía neo-liberal porque estaban buscando un 'consenso al centro'. Han aceptado la pretensión de que no había alternativa a la forma de globalización neoliberal presente y están solamente tratando de gestionarla de un modo 'más humano'.

Usted defiende lo que llama 'una esfera agonista'. El énfasis ahi es en el reconocimiento del desacuerdo y la transformación de los antagonistas en adversarios, más que forjar un acuerdo consensual. ¿Cuáles considera son los límites del agonismo? ¿Hay una diferencia estricta entre antagonismo y agonismo?

Precisamente, para desafiar la idea que la política consiste en tratar de alcanzar el consenso a través de procesos deliberativos he desarrollado mi enfoque agonista. Mi argumento es que la política democrática requiere de la existencia de una 'esfera pública agonista', donde la confrontación pueda tomar lugar entre proyectos hegemónicos conflictivos. Una vez que es reconocido que los conflictos antagonistas son inerradicables y que un consenso racional es imposible en política, la tarea de la democracia política es suministrar las instituciones y prácticas que permitirán a esos 
conflictos tomar una forma agonista en la cual los oponentes no sean tratados como enemigos a ser eliminados, sino como adversarios. Como to he subrayado repetidamente, la dimensión antagonista no desaparece en una relación agonista y los adversarios son, por así decirlo, 'enemigos legítimos'. Ellos son conscientes que, en el conflicto en el que están comprometidos, las diferentes posiciones nunca pueden ser reconciliadas -de ahí el elemento antagonista- pero reconocen la legitimidad de sus oponentes en la lucha por la victoria de sus posiciones. Ahí radica la diferencia entre una relación antagonista y una agonista. En un nivel teórico es, entonces, imposible distinguir completamente antagonismo y agonismo. El agonismo es una forma 'domesticada' o 'sublimada' de antagonismo, pero el antagonismo está siempre ahí y puede emerger en cualquier momento. Cuando vemos la cuestión al nivel de lo político, es necesario en un determinado momento que sea posible distinguir entre antagonistas y adversarios. En verdad, las demandas de los antagonistas no pueden ser parte de la lucha agonística. Como he argumentado, debe existir entre los adversarios un 'consenso conflictivo', consistente en un acuerdo sobre principios ético-políticos que sea parte de la asociación política, pero un disenso acerca de su interpretación. Aquellos que no comparten esos principios ético-políticos no son adversarios, sino enemigos cuyas demandas no son consideradas legítimas. Por supuesto, esa distinción no es fácil de hacer. En la mayoría de los casos, resulta de una decisión política basada en consideraciones pragmáticas y es por esa razón que siempre debe estar abierta a la impugnación.

El concepto de 'lo político' aparece de modo considerable en su trabajo desde los 90 en adelante. Usted deriva mucho de su comprensión de este concepto de Carl Schmitt y su distinción entre 'amigo' y 'enemigo'. ¿Ve margen para alguna otra diferenciación en el concepto de lo político?

De acuerdo a mi enfoque, 'lo político' se refiere a una dimensión antagonista que existe en las sociedades humanas. Se manifiesta en conflictos que no tienen una solución racional. Esta es, en efecto, una concepción que concuerda con el concepto de 'lo político' como una discriminación entre amigo/enemigo. Como Schmitt, mi posición pertenece a lo que Oliver Marchart llama el punto de vista 'disociativo' de lo político, el 
cual enfatiza la dimensión de conflicto y que distingue de la visión 'asociativa', la cual visualiza lo político como 'actuar en concierto'.

También ha propuesto distinguir entre 'lo político' y 'la política' para poner en primer plano la diferencia entre el nivel ontológico y óntico. De acuerdo a mi abordaje, lo político no está localizado al nivel de las prácticas concretas. Es una afirmación ontológica acerca de la existencia de una negatividad radical. La política, por otro lado, está localizada en el nivel óntico y consiste en diversas prácticas a través de las cuales un orden específico es establecido para organizar la coexistencia humana, de acuerdo a diferentes principios ético-políticos. Al nivel de la política es que uno puede hacer la distinción entre enemigos y adversarios. En otras palabras, esta negatividad radical, que impide la totalización de la sociedad, puede expresarse al nivel óntico a través de diferentes formas de conflicto: sea como amigo/enemigo (llamémoslo propiamente 'antagonista') o como agonismo, que es un conflicto entre adversarios. Como to he indicado la dimensión antagonista no desaparece en el agonismo, esta meramente domesticada o sublimada. Una de mis tesis claves es que el desafío para la política democrática es suministrar las instituciones que permitirán a los conflictos tomar una forma agonista. De otro modo, esos conflictos pueden emerger como antagonismos que podrían destruir la asociación política.

A través de sus escritos - desde Hegemonía y Estrategia Socialista, pasando por su crítica a la política de la 'tercera via'- usted ha sido profundamente crítica de la social democracia en Europa. ¿Puede la política parlamentaria, realistamente, alguna vez, formar parte de la estrategia radical democrática que defiende?

Es cierto que uno puede encontrar a través de todos mis trabajos una crítica a la social democracia, pero nunca es un total rechazo. El proyecto de democracia radical que presentamos en Hegemonía y Estrategia Socialista puede ser entendida como una radicalización de la social democracia. En el momento de escribir el libro, al comienzo de los 80, éramos críticos del Estado de Bienestar por el modo burocrático en que había sido implementado y por su incapacidad de tomar en cuenta las demandas de los movimientos sociales. Argumentamos que los derechos sociales y económicos 
necesitaban ser profundizados y extendidos, de modo de incluir más áreas de la vida social. Pero insistimos que este proceso no requería una revolución y debía ser visto como una crítica inmanente de las instituciones liberal democráticas. En ese tiempo la hegemonía social demócrata aún no había sido destruida por el thacherismo y era todavía posible el proyecto de la izquierda en términos de la radicalización y profundización de los valores social demócratas. Hoy la situación es, por supuesto, diferente y en verdad mucho peor. Con la casi sin respuesta hegemonía del neoliberalismo, muchos de los beneficios de la social democracia han sido arrebatadas. Nos encontramos en la paradójica situación de tener que defender las mismas instituciones que criticábamos antes por no ser suficientemente democráticas. Y también las hemos defendido contra la autoproclamada 'centroizquierda' que, bajo la pretensión de 'modernizarlas' han liquidado a la social democracia. A pesar de sus insuficiencias, los gobiernos laboristas previos al thatcherismo fueron ciertamente más progresistas que el Nuevo Laborismo. La actual política de centro izquierda ha aceptado el terreno establecido por decenios por la hegemonía neo-liberal y han abandonado cualquier intento de desafiar la forma de globalización neoliberal. Una de las tareas de hoy es recuperar y radicalizar los ideales social demócratas. Veo esta lucha al modo de lo que Gramcsi llamó 'guerra de posición', una lucha apuntando y desafiando los diversos puntos nodales a través de los cuales la actual hegemonía está asegurada. Contrariamente al punto de vista, muy de moda hoy, de que la 'multitud' podría abandonar la política tradicional existente y auto organizarse lejos del estado y las instituciones políticas, estoy convencida que la política parlamentaria tiene un papel que jugar en una estrategia democrática radical. Por supuesto, los partidos necesitan ser drásticamente transformados para hacerlos más representativos de las demandas democráticas. Pero representan una importante arena donde los ciudadanos pueden llegar a comprometerse en la lucha adversarial, y proveen un terreno necesario para el establecimiento de una verdadera política agonista. Esto es por lo que la 'guerra de posición' requiere de la creación de sinergia entre las luchas parlamentarias y extraparlamentarias, el trabajo junto de las instituciones políticas tradicionales como los partidos y sindicatos con los diferentes movimientos sociales.

Usted ha llamado a la izquierda a reconocer el papel de las pasiones en la constitución de las identidades políticas. ¿Pero no es éste un terreno más seguido por la 
derecha y sus apelaciones a las supuestas afecciones no criticables -o lo que Gramcsi podría llamar 'sentido común'?

La idea de que la movilización de las pasiones es más seguida por la derecha y de que la izquierda no debería comprometerse con el dominio de los afectos, es precisamente el punto de vista que estoy desafiando. Creo que ésta es una de las causas de la presente incapacidad de los partidos de izquierda para que la gente se identifique con su proyecto y despierte su entusiasmo. La pretensión de que la política democrática debería aspirar al logro de un consenso racional a través de procesos de deliberación que asegurarían la imparcialidad de los resultados es, desde mi punto de vista, una concepción profundamente equivocada de la naturaleza de la democracia. Si aceptamos, como afirmo, que la política es inherentemente partidista y que la creación de un 'nosotros' requiere necesariamente la determinación de un 'ellos', el asunto central no puede ser la creación de un 'nosotros' completamente inclusivo sin el correspondiente 'ellos'. Como he argumentado, usando la noción de 'exterior constitutivo', esa es, en verdad, una imposibilidad conceptual. Lo que está en juego en la política democrática es la naturaleza del 'ellos' y el modo en que es construido. En ese respecto, las intuiciones del psicoanálisis son absolutamente cruciales y ponen de relieve el papel central jugado por los afectos y deseos en la construcción de las identidades colectivas. Estoy de acuerdo con Yannis Stavrakakis en que el enfoque discursivo necesita hacer lugar a los elementos de 'goce' para captar la naturaleza y resiliencia de las afecciones alrededor de las cuales las identificaciones específicas son establecidas.

Con respecto al significado de la noción gramcsiana de 'sentido común' quisiera insistir que es siempre el resultado de una hegemonía dada, cuyo sistema de valores ha llegado a estar tan sedimentado que su origen político ha sido borrado. Es así como cierta concepción del mundo e ideas específicas acerca de qué es posible y deseable aparece como expresión de un 'orden natural'. No hay nada de 'natural' en el sentido común y éste puede ser siempre transformado a través de prácticas contra-hegemónicas. Hemos sido testigos en Bretaña con el thatcherismo, cómo un sentido común ha sido reemplazado por otro neoliberal. Este sentido común ha impuesto la visión de que no hay alternativa a la globalización neoliberal, de que es un destino al cual debemos someternos. Es crucial para la izquierda desarticular dicha hegemonía y producir otra 
forma de sentido común. Para que esa estrategia sea exitosa requiere reconocer la dimensión afectiva presente en las formas presentes de identificación y suministrar formas alternativas de adhesión. No quiero negar que los argumentos racionales podrían contribuir a esa lucha, pero ciertamente no juegan el papel central. Estoy convencida que la retórica, abordando capas más complejas de nuestra personalidad, puede tener mucho mayor impacto en proveer nuevas formas de subjetividad.

Recientemente, ha discutido el lugar del arte y de los artistas en la formación de una hegemonía radical democrática. ¿Qué tipo de contribución crítica cree que los artistas o, la cultura popular en general, puede jugar en dicha política? ¿Cuán receptivos encuentra en los artistas a sus ideas?

He estado siempre particularmente interesada en el papel de las prácticas culturales y artísticas porque es uno de los lugares donde la subjetividad es construida. Si aceptamos que las identidades no están nunca simplemente dadas, sino que estamos siempre tratando con identificaciones, entonces necesitamos poner especial atención a aquellos lugares donde la identificación se forma. Pienso que el campo de la cultura y del arte son muy importantes en este sentido. En verdad, ninguna hegemonía podría ser establecida sin su contribución ya que constituyen un terreno privilegiado para la construcción del 'sentido común'. Pero en las condiciones del capitalismo post-fordista su papel ha llegado a ser absolutamente decisivo porque éste se basa crecientemente en técnicas semióticas para crear modos de subjetivación necesarias para su reproducción. Para mantener su hegemonía, el presente sistema capitalista necesita la constante movilización de los deseos de la gente y formar su identidad. Esto es logrado en parte a través de la publicidad, pero los medios juegan un papel crucial. Por eso el ámbito cultural ocupa un lugar estratégico en la política de hoy. Muchos productores culturales se han hecho conscientes de esta situación y pienso que esa es la razón del interés que mi trabajo ha encontrado en esos círculos. Al comienzo estaba sorprendida de ser invitada por museos y una variedad de instituciones artísticas, pero entonces comencé a comprender cómo mi concepción agonista de espacio público permitía a los artistas visualizar la naturaleza política de sus prácticas. Mucha gente me ha dicho que ellos trataron primero de usar la idea habermasiana de esfera pública para situar sus intervenciones en un contexto político, pero que eso los dejó insatisfechos. En el 
enfoque agonista, por el contrario, encontraron una manera de visualizar qué papel podrían jugar en una lucha contra-hegemónica.

Prefiero hablar de prácticas artísticas 'críticas' para referirme a las prácticas cuyo objetivo es desafiar la hegemonía dominante porque cuando reconocemos que las prácticas artísticas y culturales siempre juegan un papel en la constitución y la reproducción de la hegemonía, se pone de manifestó que tienen siempre una dimensión política. La distinción entre arte político y no político necesita ser, entonces, abandonado puesto que no hay arte que sea completamente apolítico. Desde una perspectiva agonista, las prácticas críticas son aquellas que tienen por propósito fomentar el disenso, y presentar alternativas reprimidas por la hegemonía dominante. Lo que está en la palestra es la transformación del modo en que percibimos el mundo común, la emergencia de un sentido común diferente y la construcción de nuevas subjetividades. Esto puede ser hecho en una variedad de formas y yo estoy definitivamente a favor de una comprensión pluralista de como concebir la naturaleza de las prácticas artísticas críticas. Algunos privilegian lo sublime sobre lo bello, que rechazan como reaccionario. Considero que esto es un error porque el arte bello puede ser muy subversivo. Otros presentan la transgresión como el gesto más radical del arte. Pero la transgresión no es necesariamente subversiva y, de hecho, las fuerzas del mercado aman la transgresión, prosperan con ella.

Eventos recientes, como la 'Primavera Árabe' de 2011, demuestran el continuo entusiasmo por las luchas democráticas alrededor del mundo. ¿Qué ve como lo significativo de esos eventos?

Lo que está ocurriendo el Medio Oriente es muy importante y esas revueltas populares tendrán sin duda consecuencias de largo alcance. Pero es muy temprano para saber cuáles serán sus resultados. Mientras tanto, es interesante ver cómo son celebradas de muy diferentes lugares, los que están tratando de presentarlos como la prueba de que sus propias orientaciones son las correctas. En USA los neo-conservadores pretenden que esas revueltas justifican la estrategia de democratización de George W. Bush; para Alain Badiou son la manifestación de 'la idea comunista' y él pretende que no tienen 
nada que ver con la democracia; Hardt y Negri, por su parte, las presentan como una típica expresión de la Multitud. Claramente, lo que ellos desafían es la perspectiva esencialista de acuerdo a la cual las sociedades árabes estaban destinadas a ser gobernadas por autócratas. Pero el tipo de orden que reemplazará a esos autócratas está aún sin decidir. Un resultado realmente progresista requerirá que los actores de esas revueltas sean capaces de establecer cadenas de equivalencia entre sus varias demandas y que encuentren modos de institucionalizar sus luchas múltiples. Una cosa es derribar a un autócrata o a un gobierno impopular, otra es construir una alternativa democrática. De hecho, la 'Primavera Árabe' suministra un muy buen ejemplo de los asuntos que estaba discutiendo antes cuando criticaba la estrategia de "éxodo" de no reconocer la necesaria fase de institucionalización y por desechar el papel que los partidos pueden jugar en la transformación de la configuración de las relaciones de poder y el establecimiento de un diferente tipo de estado.

Seguro, esta cuestión no es sólo relevante para el Medio Oriente, es crucial para las revueltas que están actualmente ocurriendo en Europa. Aunque soy muy empática con el movimiento de los 'indignados' en España, estoy realmente preocupada cuando los oigo reivindicar una democracia participativa sin líderes ni partidos y que el objetivo de esas formas participativas directas debería ser alcanzar un consenso inclusivo. Esto es sin, duda, bien intencionado, pero como ya hemos sido testigos en las elecciones regionales, hasta aquí el resultado de semejante enfoque anti-político ha sido causar la derrota de los socialistas del PSOE y su reemplazo por el Partido Popular de derecha. No hay duda que los partidos de centro izquierda existentes son completamente incapaces de confrontar los desafíos puestos por el modelo neo-liberal de globalización, pero la solución no es acabar con la democracia representativa, esperando que esto abrirá el camino al advenimiento de la 'democracia absoluta' de la multitud defendida por Hardt y Negri.

Como usted anota, algunos recientemente defienden un retorno a la idea de ‘comunismo' como el modo de subvertir el dominio del pensamiento y la práctica neoliberal. ¿Cómo responde a eso? 
Aunque concuerdo con la necesidad de retar la ampliamente aceptada pretensión de que el fracaso desastroso del modelo soviético nos fuerza a rechazar enteramente el proyecto emancipatorio, creo que hay importantes lecciones a aprender de esta trágica experiencia y esto llama a serias reformulaciones de algunos principios del proyecto comunista. Sería, en verdad, muy fácil simplemente declarar que 'el socialismo realmente existente' representa una realización defectuosa de un ideal que aún no se ha implementado verdaderamente. Sin duda, muchas de las razones por las cuales aquel se extravió podrían haber sido evitadas y las condiciones actuales podrían proveer un terreno más favorable. Pero algunos de los problemas que encontró no pueden ser reducidos a un simple asunto de aplicación y ellos tienen que ver con el modo en que este ideal fue conceptualizado. Para permanecer fiel a los ideales que inspiraron los distintos movimientos comunistas, es necesario examinar cómo concibieron sus objetivos y comprender por qué esos ideales pudieron extraviarse de modo tan desastroso,

Estoy convencida que es la idea misma de 'comunismo' la que necesita ser problematizada porque está fuertemente connotada con la visión anti-política de una sociedad donde los antagonismos han sido erradicados y donde la ley, el estado y otras instituciones reguladoras habrían llegado a ser irrelevantes. De acuerdo a mi enfoque antagonista, la política pluralista democrática comienza con el reconocimiento que el pueblo está dividido y que el gobierno democrático del pueblo no puede ser absoluto. Toda forma de orden es la expresión de una hegemonía dada, lo que significa que es el gobierno de una específica forma de construcción del 'pueblo'. Por eso la democracia requiere la existencia de instituciones que permitan que una hegemonía existente sea desafiada. En este sentido argumento que hay una dimensión necesaria de populismo en la política democrática, puesto que lo que está en juego es la construcción de un pueblo. El asunto central es cómo este pueblo va a ser construido y esto es acerca de lo que trata la lucha agonística. Es un serio error identificar el populismo con la política de derecha y creer que la izquierda debería evitar comprometerse en ese terreno. Lo que necesitamos urgentemente hoy es el desarrollo de partidos de izquierda populistas, capaces de dar expresión institucional a las demandas democráticas de los numerosos grupos que aspiran a una alternativa a la actual hegemonía neo-liberal. 